\title{
A NOTE ON STRONG APPROXIMATION OF FOURIER SERIES AND EMBEDDING THEOREMS
}

\author{
R. J. LE AND S. P. ZHOU ${ }^{1}$
}

Abstract. The present paper proves embedding results which arise from strong approximation by Fourier series and generalizes a theorem of Tikhonov under the ultimate MVBV condition.

Mathematics subject classification (2000): 42A20, 42A32.

Key words and phrases: trigonometric series, mean value bounded variation, strong approximation.

\section{REFERENCES}

[1] T.W. Chaundy AND A.E. JolliFFE, The uniform convergence of a certain class of trigonometric series, Proc. London Math. Soc., 15(1916), 214-216.

[2] L. LEINDLER, On the uniform convergence and boundedness of a certain class of sine series, Anal. Math., 27(2001), 279-285.

[3] L. LEINDLER, A new class of numerical sequences and its applications to sine and cosine series, Anal. Math., 28(2002), 279-286.

[4] S.P. ZHOU, P. ZHOU AND D.S. YU, Ultimate generalization of monotonicity for uniform convergence of trigonometric series, arXiv: math.CA/0611805 v1 November 27, 2006, preprint.

[5] L. LeINDLER, Some inequalities of Hardy-Littlewood type, Analysis Math., 20 (1994), 95-106.

[6] S. TIKHONOV, Strong approximation of Fourier series and embedding theorems, Anal. Math., 31(2005), 183-194.

[7] R.J. LE AND S.P. ZHOU, A new condition for the uniform convergence of certain trigonometric series, Acta Math. Hungar., 108(2005), 161-169.

[8] L. LEINDLER, A newer class of numerical sequences and its applications to sine and cosine series, Anal. Math. 33(2007), 37-43.

[9] L. LEINDLER, Embedding relations of Besov classes, Acta Sci. Math. (Szeged) 73(2007), 133-149.

[10] L. LEINDLER, Necessary and sufficient conditions for uniform convergence and boundedness of a general class of sine series, Austral. J. Math. Anal. Appl. (Electronic), 4:1(2007), Article 10. 